\title{
Are South African Speech-Language Therapists adequately equipped to assess English Additional Language (EAL) speakers who are from an indigenous linguistic and cultural background? A profile and exploration of the current situation
}

\begin{tabular}{|c|c|}
\hline \multicolumn{2}{|c|}{$\begin{array}{l}\text { Authors: } \\
\text { Thandeka Mdlalo }{ }^{1} \\
\text { Penelope Flack } \\
\text { Robin Joubert }\end{array}$} \\
\hline \multicolumn{2}{|c|}{$\begin{array}{l}\text { Affiliations: } \\
{ }^{1} \text { Speech Therapist, } \\
\text { Livingstone School, Durban, } \\
\text { South Africa }\end{array}$} \\
\hline \multicolumn{2}{|c|}{$\begin{array}{l}{ }^{2} \text { Discipline of Speech } \\
\text { Language Pathology, } \\
\text { University of KwaZulu-Natal, } \\
\text { South Africa }\end{array}$} \\
\hline \multicolumn{2}{|c|}{$\begin{array}{l}{ }^{3} \text { Discipline of Occupational } \\
\text { Therapy, University of } \\
\text { KwaZulu-Natal, South Africa }\end{array}$} \\
\hline \multicolumn{2}{|c|}{$\begin{array}{l}\text { Corresponding author } \\
\text { and email: } \\
\text { Robin Joubert } \\
\text { joubertr@ukzn.ac.za }\end{array}$} \\
\hline \multicolumn{2}{|c|}{$\begin{array}{l}\text { Dates: } \\
\text { Received: } 23 \text { May } 2015 \\
\text { Accepted: } 29 \text { Nov. } 2015 \\
\text { Published: } 18 \text { Mar. } 2016\end{array}$} \\
\hline \multicolumn{2}{|c|}{$\begin{array}{l}\text { How to cite this article: } \\
\text { Mdlalo, T., Flack, P., \& } \\
\text { Joubert, R. (2016). Are South } \\
\text { African Speech-Language } \\
\text { Therapists adequately } \\
\text { equipped to assess English } \\
\text { Additional Language (EAL) } \\
\text { speakers who are from an } \\
\text { indigenous linguistic and } \\
\text { cultural background? A } \\
\text { profile and exploration of the } \\
\text { current situation. South } \\
\text { African Journal of } \\
\text { Communication Disorders, } \\
\text { 63(1), Art. \#130, } 5 \text { pages. } \\
\text { http://dx.doi.org/10.4102/ } \\
\text { sajcd.v63i1.130 }\end{array}$} \\
\hline \multicolumn{2}{|l|}{ Read online: } \\
\hline 口ita & $\begin{array}{l}\text { Scan this QR } \\
\text { code with your } \\
\text { smart phone or } \\
\text { mobile device } \\
\text { to read online. }\end{array}$ \\
\hline
\end{tabular}

This article presents the results of a survey conducted on Speech-Language Therapists (SLTs) regarding current practices in the assessment of English Additional Language (EAL) speakers in South Africa. It forms part of the rationale for a broader $(\mathrm{PhD})$ study that critiques the use of assessment instruments on EAL speakers from an indigenous linguistic and cultural background. This article discusses an aspect of the broader research and presents the background, method, findings, discussion and implications of the survey. The results of this survey highlight the challenges of human and material resources to, and the dominance of English in, the profession in South Africa. The findings contribute to understanding critical factors for acquiring reliable and valid assessment results with diverse populations, particularly the implications from a cultural and linguistic perspective.

\section{Background to the research survey}

This article presents an aspect of a larger PhD study, the aim of which was to critically evaluate and interrogate the use of language assessment tools, in their current form, within the South African context and to produce guidelines for adaptations to these tools that will better accommodate English Additional Language (EAL) speakers. These guidelines and principles could be used by language professionals to manage the assessment process and interpretation of findings from EAL speakers in a more accurate, appropriate and equitable manner. The term 'EAL speaker' is used here to specifically refer to South African multilinguals who are non-mother tongue speakers of English and are from indigenous language and cultural backgrounds ${ }^{1}$.

The larger study makes use of a specific screening tool as a model, to exemplify and illustrate the argument. In this study, the cultural and linguistic relevance of this commonly used screening tool is interrogated from four different viewpoints: firstly, the perspective of the children, who are the target population of the tool; secondly, that of the parents and community, who play a significant role in the socialisation of the children; thirdly, from the perspective of the academics from an indigenous language and cultural background, who provide an academic perspective of the tool; and, finally, that of Speech-Language Therapist (SLT) practitioners who administer the tool and interpret the findings. As language assessments are conducted on people who exist within a cultural context, the cultural capital is embedded in language (Peltier, 2010; Seidman, 2008; Westby, 2009). Since the larger study focuses on the relationship between language and culture and adopts an ecological approach to the problems addressed in the study, a conceptual model that encompasses a strong ecological and cultural component was selected; that is Taylor's (1986) cultural framework for viewing normal and pathological communication.

As part of this larger study, a national survey was conducted with SLTs to establish current practices in assessment and intervention, training and challenges experienced when working with a client who is an EAL speaker.

1 Not a homogenous group there may be inter- and intra-linguistic and cultural variability

Copyright: @ 2016. The Authors. Licensee: AOSIS. This work is licensed under the Creative Commons Attribution License. 
The discipline of Speech Language Pathology (SLP) has a clientele, both in South Africa and globally, which is becoming increasingly multilingual and multicultural (Jordaan, 2008; Williams \& McLeod, 2012; Wium, 2010). The assessment of diverse populations needs to take into account and to accommodate this diversity of languages and cultures (Gopaul-McNicol \& Armour-Thomas, 2002; McLeod, 2014; Tabors, 2008). The provision of a culture-fair assessment, however, presents many challenges to the profession (Caesar \& Kohler, 2007; Landsberg, 2005; McLeod, Verdon \& Bowen, 2013; Pillay, 2003). These include the limited knowledge and understanding that therapists have of the cultures and language groups from which their clientele may come. Knowledge of the language and cultural background of clients is significant for the therapist as it influences the outcome of assessment and interpretation of their findings, especially when the therapist is likely to use their own worldview as a basis for this process. It also aids the SLT in discriminating between a language disorder and language difference in EAL speakers (N. Miller, 1984; Thordardottir, 2011).

Language pathology may include: difficulty in understanding or expression of the meaning of language, problems with understanding or appropriate use of the grammatical or morphological (involving units of meaning) rules, appropriate use in social context and problems with speech sounds, patterns or rules of organisation (Shipley \& McAfee, 2004). The difficulties described here manifest in whatever language the individual uses. It is thus a language problem and not a second language (L2) difficulty. On the other hand, there may be language differences in the production by the individual, in the process of learning a L2 (i.e. undergoing bilingualism). These differences, which may be perceived as errors by a non-informed ear, will only manifest in the L2 or language being developed rather than the mother tongue. They may be influenced by factors such as language, culture and frame of reference.

Appropriate training plays a crucial role in facilitating increased linguistic and cultural understanding of the client's background (Du Plessis, 2010; Higgs, 2010). As these challenges are relevant for the South African context there is a need for research to address the gap in the assessment of our diverse population. This is the rationale for the survey, the outcome of which is discussed in this article.

\section{The research method}

The broader PhD study used a mixed methods approach with multiple data collection methods such as a survey, focus groups, individual interviews, test administration and consensus methods. The methodological design was comprised of two phases with the national survey being part of the preparatory phase, in order to set the foundation for and support the rationale for the research. Apart from establishing the assessment and therapeutic interventions that SLTs use with their clientele, the survey also assisted in providing an indication of the profile of the South African SLT.
A national survey of 1000 SLTs, registered with the Health Professions Council of South Africa (HPCSA), was thus conducted using random sampling.

Questionnaires with open and closed-ended questions on areas related to employment, clients, caseload, choice of language for practice, current practices in assessment and intervention, training and challenges were sent to SLTs on the register. Firstly, a pilot study was conducted by sending 100 questionnaires to SLTs (10\%) from this national register and the questionnaire was revised, taking into account these responses. Based on the responses received, changes were made, such as rephrasing of ambiguous questions on language use and current management and extension of some of the options provided in questions on caseload, employment and experience with EALs.

The survey questionnaires were then sent to 1000 HPCSA registered SLTs via the postal service and a $15 \%\left(\sum 150\right)$ response rate was achieved. Despite the relatively low response rate, the results are consistent with findings of global and local research (Jordaan, 2008; Von Dulm \& Southwood, 2013), which had similar response rates. Data were analysed using the Statistical Package for Social Sciences (SPSS 18). The data were organised into simple frequencies and presented in tables and graphs.

\section{Results of the survey}

The results of the survey show that $99 \%$ of SLTs sampled were from English or Afrikaans speaking backgrounds and competent in these languages (Figure 1). Furthermore, $89 \%$ of these SLTs had EAL speakers in their caseload and $86 \%$ of the SLTs used English in the assessment of these EALs. The results also suggest that English standardised language assessment tools, which have been normed on populations predominantly in the US and UK and are inappropriate for EAL speakers, remain the tests most commonly used by SLTs to assess this population and they are administered in English.

There are several reasons given by the therapists for the choice of English in assessments, but the most common is the therapist's self-proclaimed restricted competence in other African languages, as reflected in the quotes below:

'I feel equipped when the goal is to improve English language comprehension and expression'.

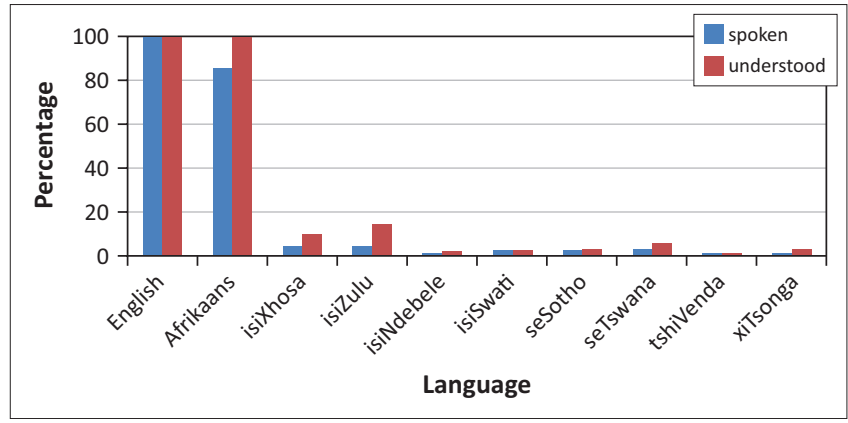

FIGURE 1: A bar chart showing the language competence percentages of SLTs in SA (Data to be interpreted with caution due to low response rate). 
'I only work in English medium schools where I have an understanding of culture or background and thus sensitivity thereof'.

'I feel equipped because I don't take on children if therapy is not in English'.

'My level of competence in understanding, speaking and thinking about all languages (except English) is insufficient in providing quality accountable service'.

Although some of the therapists are content with the use of English, as reflected in their responses, others expressed some concerns:

'Assessment tools and programmes are foreign to these children (referring to EAL speaking children) regarding the language as well as cultural barriers'.

'There are several reasons why these assessment tools present with these barriers and these include a different language, culture, experience or dialect'.

\section{Discussion and implications of the results}

Because of the low response rate to the questionnaires, the findings should be viewed with some caution in terms of conclusiveness. They do however provide an interesting insight into the direction of a broader picture of the profile of SLTs and their test usage in SA.

The survey findings suggest that EAL speakers are currently mostly being assessed by SLTs who come from different linguistic and cultural backgrounds to those of the clients (SASLHA, 2012, 2013; Von Dulm \& Southwood, 2013). This information accentuates the issue of the relationship between language and culture. Language represents a powerful tool of self-definition and expression and becomes a means through which various cultural and social groups can find unique expression (Han \& Price, 2015, Jandt, 2000; Ji, Zhang \& Nisbett, 2004; Tabors, 2008). It can thus be argued that language is a cultural phenomenon (Ball \& Peltier, 2011; Riley, 2007; Sardar \& Van Loon, 2004). Bearing this in mind, it becomes essential for professionals in the language field to understand and always draw on mother tongue, sociocultural meanings when involved in the assessment of language of multilingual and multicultural populations (Gopaul-McNicol \& Armour-Thomas, 2002; Solarsh \& Alant, 2006; Westby, 2009). In South Africa, the majority of EAL speakers use an African language as their mother tongue (http://www.statssa.gov.za), and the majority of SLTs do not. The survey results indicate that EAL speakers are thus currently being evaluated by SLTs who do not speak or understand an African language. In addition, feedback on the questionnaire also reveals that SLTs have restricted understanding of the cultures linked to these languages. It can thus be assumed that the SLT will use their own linguistic and cultural background as a frame of reference for interpreting the assessment results and this in turn may further influence the language choice and use in assessment as well as interpretation of results.
The picture thus emerging from the results of the survey places the SLT in a very powerful position as they can attach their own cultural and linguistic worldview to the meaning of the assessment and criteria for success. This powerful position further raises the question as to whether the meaning that the SLT attaches to their assessment, serves the interests of justice and equality as they relate to the client. Issues of justice and equality underpin current discussions within the profession pertaining to hegemonic discourses, language and practices that reproduce them (Kathard \& Pillay, 2013, 2015).

The nature and number of comments from some of the respondents suggest that they concur that the current situation is not ideal and indicate the need for a greater research effort into the creation of more culturally and linguistically relevant language assessment materials for EAL speakers in South Africa.

As a result of the challenges mentioned by the SLTs in the survey, specifically a paucity of culturally and linguistically relevant tests developed for the South African population (Naudé, Louw \& Weideman, 2007; Pascoe \& Norman, 2011), most evaluations are conducted using tests developed and normed on populations that are predominantly from the US or UK. That these tests are not ideal in their current form for assessing a South African EAL speaker who is from an indigenous language and cultural background goes without saying and this is confirmed by research into language development and assessment (Caesar \& Kohler, 2007; Gopaul-McNicol \& Armour-Thomas, 2002; Moro, 2008; Pierce \& Williams, 2013). Tests currently used by SLTs in South Africa are predominantly based on a linguistic, cultural and social context that is largely European and American. The guidelines for the administration of these tests do not refer to the South African multilingual and multicultural population. The test developers thus do not expect them to be used on populations outside of those stipulated in the test.

One of the reasons that the SLTs provided for mostly conducting the assessment and therapy of EAL speakers in English is the demand for the use of English by the parents of the EAL speaking children. These demands are linked to the perception by parents of EAL children that English is the language linked to progress in education. Despite the recognition of 11 official languages in SA, English remains the dominant language in all sectors of society (Burger, 2011; Green, 2008; Kamwangamalu, 2000; Landsberg, 2005; Muendane, 2006), including education (Republic of South Africa, 2011). Many African EAL speaking children from an indigenous language and cultural background are thus taught in settings where English is the medium of instruction (MoI). The language of learning and teaching (LOLT) in many South African schools is English (Lafon, 2007; Landsberg, 2005). Many SLTs therefore try to justify their persistence in assessment and intervention in English even for EAL speakers, the evidence of which is clear in the survey results, which showed that $86 \%$ of the SLTs used English in language assessments and therapy. 
The results of this survey are particularly crucial, because of the many EAL speakers from indigenous cultural and linguistic backgrounds in South Africa who are in schools where English is the MoI and who are referred by teachers for language assessments to SLTs. Even though the curriculum may be presented in English, this is not the mother tongue of these South African children, nor is their cultural background reflected (Higgs, 2010; Landsberg, 2005; Ntuli, 2002).

African language and culture influences the knowledge and belief system of the EAL speaker (Lemmer, Meier \& Van Wyk, 2006; Metz \& Gaie, 2010) and therefore influences their response to the tests, which have been predominantly normed on US or UK populations, societies whose language and culture is different from theirs (Higgs, 2003; Kroes, 2005; Makgoba, 1999; Semali, 1999). Therefore, the background, values and stories of the EAL speaker, such as found in traditional oral African culture manifesting in African signs and symbols (Maathai, 2009; Mutwa, 1998), tend to be disregarded, devalued, ignored or only superficially addressed (D. Miller, 2012) when resources for evaluations do not reflect the African experience.

As the majority of EAL speakers in South Africa are African language mother tongue speakers, it can be said that the child is treated as a tabula rasa when the African worldview (Behrens, 2010; Mucina 2013; Ntuli, 1999, 2002) they bring is ignored. The children's choice, based on their frame of reference, is excluded as an option in the assessment tool scoring system. The outcome may likely thus create a distorted reflection of the language ability of an EAL speaker from an indigenous language and cultural background and the SLT may thus, unintentionally, pathologise a child who presents with a language difference.

\section{Conclusion}

The results of the study indicate that the average SLT assessing an EAL child is still predominantly either an English or Afrikaans speaking woman, who is not competent in an African language. Saville-Troike (1986, p. 48) maintains that 'whether we realise it or not, each of us sees the world from a culturally conditioned perspective that we share with the other members of the group'. Thus, the frame of reference of these SLTs is based upon their own socio-cultural background, which in turn influences their interpretation of the child's response. These findings have implications for the selection and training of SLTs in South Africa and suggest a direction for postgraduate research in this discipline. The current recruitment of African language speakers for training in the profession needs to be intensified to accommodate the assessment and management of this population. Sections of the Speech-Language Pathology curriculum pertaining to bilingualism and cultural and linguistic diversity need to be enhanced for more effective preparation of the SLTs who will work with EAL speakers. In addition, postgraduate research that addresses these discrepancies should be encouraged.

Although it is necessary that further research be conducted to create more culturally and linguistically relevant tools for the
EAL population, the practising SLTs remain accountable for accessing research-based evidence on the assessment and management of the EAL population. Failure to do so constitutes a contravention of the profession's ethical code of conduct. It is hoped that the outcome of this research will create greater sensitivity in the application of nonstandardised language screening tests to EAL speakers in this country.

\section{Acknowledgements Competing interests}

The authors declare that they have no financial or personal relationships that may have inappropriately influenced them in writing this article.

\section{Authors' contributions}

This article is based on a $\mathrm{PhD}$ study conducted by T.M. (Speech Therapist, Durban), who was supervised by P.F. (University of KwaZulu-Natal) and R.J (University of KwaZulu-Natal). The paper was drafted by T.M. and P.F. and R.J. contributed to all sections of the final article.

\section{References}

Ball, S., \& Peltier, J. (2011). Cultural safety, relevance and effectiveness of speech and language services to indigenous children. Paper presented at the CASLPA 2011 Conference, Montreal, Canada, 27-30 April 2011.

Behrens, K. (2010). Exploring African holism with respect to the environment. EnvironmentalValues,19(4),465-484. http://dx.doi.org/10.3197/096327110X531561

Burger, D. (2011). South Africa Year Book 2010/11. (18th edn.). Johannesburg, South Africa: GCIS.

Caesar, L.G., \& Kohler, P.D. (2007). The state of school based bilingual assessment: Actual practice versus recommended guidelines. Language, Speech and Hearing Services in Schools, 38, 190-200. http://dx.doi.org/10.1044/0161-1461(2007/020)

Du Plessis, S. (2010). Redefining the role of the Speech-Language therapist in the educational context: Overcoming the barriers. Paper presented at the New Perspectives in our Profession Conference, Pretoria, South Africa, 19-20 April 2010.

Gopaul-McNicol, S., \& Armour-Thomas, E. (2002). Assessment and culture: Psychological tests with minority populations. San Diego, CA: Academic Press. http://dx.doi.org/10.1016/B978-012290451-6/50011-8

Green, P. (2008). Choice not fate: The life and times of Trevor Manuel. Johannesburg, South Africa: Penguin.

Han, E.J., \& Price, P.G. (2015). Uncovering the hidden power of language: Critical race theory, critical language socialization and multicultural families in Korea. Journa of Intercultural Communication, 44(2),108-131. http://dx.doi.org/10.1080/17475 759.2015.1028427

Higgs, P. (2003). African philosophy and the transformation of educational discourse in South Africa. Journal of Education, 30, 5-22.

Higgs, P. (2010). Towards an indigenous African epistemology of community in education research. Procedia - Social and Behavioral Sciences, 2(2), 2414-2421. http://dx.doi.org/10.1016/j.sbspro.2010.03.347

Jandt, F. (2000). An introduction to intercultural communication: Identities in a global community. (4th edn.). London, UK: SAGE.

Ji, L., Zhang, Z., \& Nisbett, R. (2004). Is it culture or is it language? Examination of language effects in cross-cultural research on categorisation. Journal of Personality and Social Language, 87(1), 57-65. http://dx.doi.org/10.1037/0022-3514.87.1.57

Jordaan, H. (2008). Clinical intervention for bilingual children. Folia Phoniatrica et Logopaedica, 60, 97-105. http://dx.doi.org/10.1159/000114652

Kamwangamalu, N.M. (2000). A new language policy, old language practices: Status planning for African languages in multilingual South Africa. South African Journal of African Languages, 20(1), 50-65.

Kathard, H., \& Pillay, M. (2013). Promoting change through political consciousness: A South African speech-language pathology response to the World Report on Disability. International Journal of Speech-Language Pathology, 15(1), 84-89. http://dx.doi.org/10.3109/17549507.2012.757803

Kathard, H., \& Pillay, M. (2015). Decolonising health professionals' education: Audiology and speech therapy in South Africa. African Journal of Rhetoric: Transitions and Transformative Rhetoric, 17, 193-227.

Kroes, H. (2005). The language perspective. In C.J. Russo, J. Beckmann, \& J. Jansen (Eds.), Equal educational opportunities (pp. 236-257). Pretoria, South Africa: Van Schaik. 
Lafon, M. (2007). Asikhulume! African languages for all, a powerful strategy for spearheading transformation and improvement of the South African Education system. Paper presented at the The Standardisation of African Languages: system. Paper presented at the The Standardisation of African Languages:
Language Political Realities, University of Pretoria, Pretoria, South Africa, 29 March 2007.

Landsberg, E. (2005). Addressing barriers to learning: A South African perspective. Pretoria, South Africa: Van Schaik.

Lemmer, E.M., Meier, C., \& Van Wyk, J.N. (2006). Multicultural education An educator's manual. Pretoria, South Africa: Van Schaik.

Maathai, W. (2009). The challenge for Africa - A new vision. London, UK: William Heineman.

Makgoba, M.W. (Ed.). (1999). African renaissance. Cape Town, South Africa: Mafube, Tafelberg.

McLeod, S. (2014). Resourcing speech-language pathologists to work with multilingual children. International Journal of Speech-Language Pathology, 16(3), 208-218. $\mathrm{http}: / / d x . d o i . o r g / 10.3109 / 17549507.2013 .876666$

McLeod, S., Verdon, S., \& Bowen, C. (2013). International aspirations for speechlanguage pathologists' practice with multilingual children with speech sound disorders: Development of a position paper. Journal of Communication Disorders, 46(4), 375-387. http://dx.doi.org/10.1016/j.jcomdis.2013.04.003

Metz, T., \& Gaie, J.B.R. (2010). The African ethic of Ubuntu/Botho: Implications for research on morality. Journal of Moral Education: Special Issue: Moral Education in sub-Saharan Africa-Culture, Economics, Conflict and AIDS, 39(3), 273-290. http://dx.doi.org/10.1080/03057240.2010.497609

Miller, D. (2012). African-centered thought on Western objectification Autoethnographic reflections. Paper presented at the International Congress of Qualitative Inquiry, University of Illinois at Urbana-Champaign, IL, 16-19 May 2012.

Miller, N. (1984). Bilingualism and language disability: Assessment and remediation San Diego, CA: College-Hill Press. http://dx.doi.org/10.1007/978-1-4899-7238-5

Moro, M.R. (2008). Transcultural issues for children and parents in a changing world. Paper presented at the 18th World Congress for the International Association for Child and Adolescent Psychiatry and Allied Professions, Istanbul, Turkey, 27 April-03 May 2008.

Mucina, D.D. (2013). Ubuntu orality as a living philosophy. The Journal of Pan African Studies, 6(4), 18-35

Muendane, M.N. (2006). I am an African: Embrace your identity, escape victimisation Pretoria, South Africa: Soultalk.

Mutwa, C. (1998). Indaba, my children. Edinburgh, Scotland: Payback Press.

Naudé, E., Louw, B., \& Weideman, A. (2007). First steps toward tools for language assessment in multilingual preschoolers. South African Linguistics Applied Language Studies, 25(4), 519-538. http://dx.doi.org/10.2989/16073610709486479

Ntuli, P. (1999). The missing link between culture and education: Are We stil chasing gods that are not our own? In M.W. Makgoba (Ed.), African Renaissance (pp. 184-199). Cape Town, South Africa: Mafube, Tafelberg.

Ntuli, P. (2002). Indigenous knowledge systems and the African Renaissance - Laying a foundation for the creation of counter-hegemonic discourses. In C. Hoppers (Ed.) Indigenous knowledge and the integration of knowledge systems (pp. 53-66). Claremont, South Africa: New Africa Books.

Pascoe, M., \& Norman, V. (2011). Contextually relevant resources in Speech-language Therapy and Audiology in South Africa: Are there any? South African Journal of Communication Disorders, 58(1), 2-5.
Peltier, S. (2010). Facilitating language and literacy learning for students with Aboriginal English dialects. Canadian Journal of Native Education, suppl. Aboriginal Englishes and Education.

Pierce, W.M., \& Williams, C. (2013). The cultural appropriateness and diagnostic usefulness of standardized language assessments for Indigenous Australian children. International Journal of Speech-Language Pathology, 15(4), 429-440.

Pillay, M. (2003). Cross-cultural practice: What is it really about. Folio Phoniatrica et Logogopaedia, 55(6), 293-299. http://dx.doi.org/10.1159/000073252

Republic of South Africa. (2011). Curriculum and Assessment Policy Statement. Pretoria, South Africa: Government Printers.

Riley, P. (2007). Language, culture and identity. London, UK: Continuum.

Sardar, Z., \& Van Loon, B. (2004). Introducing cultural studies. Royston, UK: Icon Books. SASLHA. (2012). National Speech Therapy/Audiology Forum, Free State, South Africa, 27-29 August.

SASLHA. (2013). National Speech Therapy/Audiology Forum, Gauteng, South Africa, 22-24 October.

Saville-Troike, M. (1986). Anthropological considerations in study of communication. In O. Taylor (Ed.), Nature of communication disorders in culturally and linguistically diverse populations (pp. 44-72). San Diego, CA: College-Hill Press.

Seidman, S. (2008). Contested knowledge: Social theory today (4th edn.). Victoria, Australia: Blackwell.

Semali, L. (1999). Community as classroom: Dilemmas of valuing African indigenous literacy in education. International Review of Education, 45(3-4), 305-319. http:// dx.doi.org/10.1023/A:1003859023590

Shipley, K.G., \& McAfee, J.G. (2004). Assessment in speech-language pathology: A resource manual. (3rd edn.). London, UK: Thomson Delmar Learning.

Solarsh, B., \& Alant, E. (2006). The challenge of cross-cultural assessment - The test of ability to explain for Zulu -speaking children. Journal of Communication Disorders, 39(2), 109-138. http://dx.doi.org/10.1016/j.jcomdis.2005.11.002

Tabors, P. (2008). One child, two languages. USA: Brookes Publishing.

Taylor, O. (1986). The nature of communication disorders in culturally and linguistically diverse populations. San Diego, CA: College-Hill Press.

Thordardottir, E. (2011). Bilingualism: Normal development and clinical intervention. Paper presented at the CASLPA 2011 Conference, Montreal, Canada, 27-30 April 2011.

Von Dulm O. \& Southwood, F. (2013). Child language assessment and intervention in multilingual and multicultural South Africa: Findings of a national survey. Stellenbosch Papers in Linguistics, 42, 55-76.

Westby, C. (2009). Considerations in working successfully with culturally/linguistically diverse families in assessment and intervention of communication disorders. Seminars in Speech and Language, 30(4), 279-289. http://dx.doi.org/10.1055/ Seminars in Speech

Williams, C., \& McLeod, S. (2012). Speech-language pathologists' assessment and intervention practices with multilingual children. International Journal of Speech
-Language Pathology, 14(3), 292-305. http://dx.doi.org/10.3109/17549507.201 - Language

Wium, A.M. (2010). Speech-Language Therapists in previously disadvantaged schools: Factors affecting support. Paper presented at the SASLHA Perspectives on Our Professions Conference, Pretoria, South Africa, 19-20 April 2010. 